\title{
Influence of materialism, gender and nationality on consumer brand perceptions
}

Received (in revised form): 27th July, 2005

\section{Rajeev Kamineni}

has eight years' sales and marketing experience in the book, stationery, toys and cement industries. He also has eight years' experience in marketing and entrepreneurship academia. Rajeev is a Certified Practising Marketer and Associate Fellow of the Australian Marketing Institute. He is a multiple award winning teacher at Bond University and was a member of the Best Business Plan Winning MOOT CORP ${ }^{\circledR}$ team of 1999. Rajeev currently teaches marketing and international business and is head of the Bachelors Program in International Business at the University of Western Sydney.

\begin{abstract}
This study attempts to link materialism, gender and nationality with the consumer perception of a high-priced brand of apparel. It describes the results of a survey of 104 undergraduate students in an Australian university. The work focuses on the differences in perception of a high-priced brand. It indicates that young undergraduates hold different perceptions of a brand depending on their sex and nationality. The study also examines the materialistic tendencies of customers and whether materialism is influenced by gender and nationality, especially from an Australian perspective. Materialism was measured by using the Richins and Dawson (1992) scale. Five research questions were put forward and the results indicated that there is a difference in perception of a high-priced brand between customers of different nationality and sexes.
\end{abstract}

Keywords: consumer brand perception, materialism, high-priced brands, conspicuous consumption, cross-national consumer preferences, role of possessions

Rajeev Kamineni Lecturer, School of Marketing and International Business, Bldg U2, Blacktown Campus, University of Western Sydney, Locked Bag 1797, Penrith South DC, NSW 1797, Australia Tel: +612 9852 4131; Fax: +61 29852 4246; e-mail: r.kamineni@uws.edu.au

\section{INTRODUCTION TO MATERIALISM}

Materialism is the 'devotion to material needs and desires, to the neglect of spiritual matters; a way of life, opinion or tendency based entirely upon material interests'. ${ }^{1}$ Today's world has more or less become a fully-fledged consumer society. Since the late 1950s, the topic of materialism has been widely researched, evoking mixed reactions from many consumer researchers. Several researchers came up with different forms of interpretation of materialism. The pioneer and expert in the research on materialism is Russell W. Belk. Since the 1980s, Belk has published many articles on the concept of materialism, from several angles. Although Richins, ${ }^{2}$ Richins and Dawson, ${ }^{3}$ Campbell, ${ }^{4}$ Inglehart ${ }^{5}$ and others measured the concept of materialism in different formats, Belk stands out for his originality and various interpretations of materialism. Belk interpreted materialism through comic characters like Richie Rich, Uncle Scrooge, Archie (1987), ${ }^{6}$ through worldly possessions $(1983)^{7}$ and also through trait aspects of living (1985). ${ }^{8}$ 
Materialism as a word or trait is generally viewed in a very negative sense and is clearly reflected in the various denouncements of materialism by all major world religions and in numerous other critiques. It is interesting to note from the previous research that it has been established that materialism is viewed as an evil phenomenon and that the USA is commonly viewed as a country that encourages and breeds this evil phenomenon. There are some interesting arguments put forth about materialism. One argument ${ }^{9}$ states that relationships with things alienates us from relationships with people, material desires cause property crime ${ }^{10}$ and that this planet is suffering a general degradation because of materialism. ${ }^{11}$

Attitudes to materialism are somewhat contradictory, and as such open up a new avenue for research. Indeed, if there is so much antipathy and resentment towards materialism, then why are the sales figures of the so-called 'materialistic possessions' going up year after year? Despite the various discourses against materialism, it is quite clear that consumption, which is taken to constitute good life, is increasingly becoming the focal point of life throughout the world. ${ }^{12-18}$

Against such a background, it is interesting to find out how particular brands can be regarded as materialistic and if they convey any negative connotations. At the same time, even if they convey negative connotations, are they shunned by consumers because of these connotations or are they desired by consumers to attain a certain social standing? An interesting aspect of the literature on materialism is that it tends to view materialism in a negative light or negative sense. Moreover, the literature assigns to materialists a number of characteristics that are viewed negatively in contemporary society, yet it is surprisingly silent on the obvious positive aspects of materialism such as the desire to succeed and high level of self-sufficiency.

The existing literature on materialism can be divided into three groups:

1 Acquisitions and possession-defined materialism; ${ }^{19-24}$

2 Instrumental and terminal materialism; ${ }^{25,26}$

3 Measurement of materialism through related constructs. ${ }^{27-30}$

\section{Limitations of existing research}

Materialism was commonly inferred through the use of personality traits; this presents a contradiction because unless materialism itself is considered as a personality trait, which has not been the case, it cannot be inferred through personality traits. Materialism is a highly complex construct; many of the measures do not possess adequate levels of reliability for use in anything other than exploratory research. Finally, as mentioned earlier, most measures, other than Belk's, have not involved the regular procedures of construct definition, scale refinement and validity assessment.

\section{FASHION MARKETING}

Increasingly, in fashion marketing, brands are seen as important in creating an identity, a sense of achievement and identification for consumers who are fashion conscious and materialistic. The economic value of luxury, fashion and status products is argued to be substantial. ${ }^{31}$ Mason $^{32}$ argued that people express themselves through consumption in a myriad of ways, and in this context, products and brands have the ability to communicate messages to others, in that product styles determine how consumers 
who own a particular product are perceived by others. ${ }^{33,34}$ Fashion can be viewed as an outcome that takes into account the cultural aspects as well as changes in preferences and tastes. The relationship between characteristics of both consumers and brands are becoming increasingly important marketing problems, particularly with characteristics such as materialism being a strong driver of acquiring and consuming specific types of brands. As such, this study focuses on examining the relationships between consumer characteristics, including gender, nationality and level of materialism with brand perception.

\section{THEORETICAL FRAMEWORK}

Possessions and their acquisition occupy a central role in the lives of many individuals, ${ }^{3}$ who are often termed materialists. Activities focusing on possessing and acquiring are central to materialists because they indicate success and provide happiness. It is not uncommon to be involved to some extent in the pursuit of happiness; however, it is the pursuit of happiness through acquisition rather than through other means, such as personal relationships and achievements, that distinguishes materialists. More often than not, materialists tend to judge their own and others' success by the number and quality of possessions they accumulate. The value of possessions stems not only from their ability to confer status but also from their ability to project a desired self-image and identify one as a participant in an imagined perfect life. ${ }^{35}$ Success for a materialist depends to a large extent on the possession of products that depict certain desired images.

As Mowen ${ }^{36}$ and Solomon ${ }^{37}$ suggest, some consumers emphasise the material significance of image. Having more materialistic values is associated with using possessions to convey an impression and also retaining possessions instead of disposing of them. ${ }^{38}$ By the same token, materialism places a very high importance on possessions and accords them a central role in life. ${ }^{39}$ Materialistic individuals are believed to value items that are consumed publicly and possess public meaning, rather than private, personal or subjective meanings. ${ }^{40}$ Also, it has been argued that Australia's growing preoccupation with possessions is reflected in the rise in credit card usage and consumer debt, and such consumption values as 'shop till you drop' and 'he who dies with the most toys, wins'. ${ }^{41}$ This does not imply that every consumer is materialistic, as there are significant differences between individuals' prioritisation of and attachment to possessions.

One product category that essentially fulfils these criteria in every respect is fashion clothing. Fashion clothing (apparel) is a product that is consumed publicly and possesses public meaning. Purchasing apparel satisfies various needs such as the expression of identity ${ }^{42,43}$ and self-image, ${ }^{44}$ as well as giving individuals a way to impress others. Thus, consumers who tend to pick up high-priced apparel aim to satisfy some of the above needs. The crucial dimensions of possessions for any materialist are utility, appearance, financial worth and the ability to convey status, success and prestige. All these dimensions are satisfied through the purchase of high-profile branded (and high-priced) apparel. Individuals have an understanding that a particular possession will convey a strong message or signal to the world about what and who they are. ${ }^{45}$ Customers under the age of 30 years tend to be very conscious of their image and the products they possess or acquire. ${ }^{46}$ 
High-priced apparel is a product that has a high potential for symbolic meaning. The relationship between materialism, gender, nationality and possession of high-priced apparel has not been explored, and this exploratory study attempts to fill that gap.

Therefore, focusing on materialism, gender and nationality, the following research questions are posed to examine brand perceptions:

1 Do materialistic tendencies differ between males and females?

2 Do materialistic tendencies differ between Australians and non-Australians?

3 Do brand perceptions of high-priced fashion clothing differ between males and females?

4 Does perception of high-priced fashion clothing differ between Australians and non-Australians?

5 Is there an association between consumers' materialism and their perception of brand image and personal satisfaction?

\section{METHOD}

The methodology was based on the development of a self-administered questionnaire using a convenience sample of students at an Australian university. Materialism was measured using the Richins and Dawson ${ }^{3}$ 18-item measure scale focusing on happiness, centrality and success. The survey also contained a number of statements on brand perceptions related to apparel. Brand perception was measured using a six-item measure focusing on symbol of success, happiness, image, satisfaction, prestige and high-priced exclusivity.

In total, 104 completed surveys were received and all the respondents were undergraduate marketing students under the age of 30 . The sample had 59 males and 45 females. Of the 104, 34 were Australians and 70 were non-Australian students. The data were factor analysed using principal components analysis with varimax rotation, ${ }^{47}$ and Pearson correlation. ${ }^{48}$ The research questions were analysed with $t$-tests to compare any two groups (males, females and Australians, non-Australians).

\section{RESULTS}

The preliminary factor analysis indicated that materialism contained three factors (success, happiness and centrality as identified by Richins and Dawson. ${ }^{3}$ Factor loadings ranged between 0.40 and 0.81 and reliabilities ranged between 0.69 for success, 0.64 for centrality and 0.69 for happiness. Fifty-eight per cent of the overall variance was accounted for by these three factors. The Cronbach alpha values reported by Richins and Dawson ${ }^{3}$ were 0.71 for centrality, 0.74 for success and 0.73 for happiness. The preliminary factor analysis for brand perception indicated two factors (brand image and personal satisfaction) with factor loadings ranging between 0.35 and 0.89 .

Fifty-four per cent of the overall variance was accounted for by these two factors.

\section{Materialistic tendencies}

\section{Males and females}

The results indicate that there is a difference of 0.18 between the means of males and females (see Table 1). The $t$-test

Table 1: Comparison of materialism scores

\begin{tabular}{lllll}
\hline & Mean & $\boldsymbol{p}$ & $\boldsymbol{t}$ & $\mathbf{N}$ \\
\hline Australian $_{\text {Non-Australian }}^{*}$ & 3.16 & NS & 1.109 & 34 \\
Male & 3.06 & $<70$ & & \\
Female & 2.99 & $<0.05$ & -2.095 & 59 \\
\hline
\end{tabular}

*Defined as respondents who are not citizens/residents of Australia 
Table 2: Comparison of perceptions of the Armani brand

\begin{tabular}{|c|c|c|c|c|}
\hline & & Mean & $p$ & $t$ \\
\hline Armani 1 & Male & 3.28 & NS & 0.941 \\
\hline (Symbol of success in the society) & Female & 3.09 & & \\
\hline Armani 2 & Male & 3.20 & NS & 0.904 \\
\hline (Makes owners very happy) & Female & 3.02 & & \\
\hline Armani 3 & Male & 3.03 & NS & -0.322 \\
\hline (Urge to own something new satisfied) & Female & 3.09 & & \\
\hline Armani 4 & Male & 4.10 & NS & -0.320 \\
\hline (Purchased primarily for its image) & Female & 4.15 & & \\
\hline Armani 5 & Male & 3.72 & NS & -0.591 \\
\hline (Prestigious) & Female & 3.84 & & \\
\hline Armani 6 & Male & 3.91 & NS & -0.346 \\
\hline (High-priced exclusivity) & Female & 3.97 & & \\
\hline Armani 1 & Australian & 3.30 & NS & 0.475 \\
\hline (Symbol of success in the society) & Non-Australian & 3.19 & & \\
\hline Armani 2 & Australian & 3.13 & NS & 0.137 \\
\hline (Makes owners very happy) & Non-Australian & 3.10 & & \\
\hline Armani 3 & Australian & 3.20 & NS & 0.978 \\
\hline (Urge to own something new satisfied) & Non-Australian & 3.01 & & \\
\hline Armani 4 & Australian & 3.76 & $<0.05$ & -2.578 \\
\hline (Purchased primarily for its image) & Non-Australian & 4.26 & & \\
\hline Armani 5 & Australian & 3.73 & NS & 0.355 \\
\hline (Prestigious) & Non-Australian & 3.80 & & \\
\hline Armani 6 & Australian & 3.66 & $<0.055$ & -1.941 \\
\hline (High-priced exclusivity) & Non-Australian & 4.04 & & \\
\hline
\end{tabular}

is quite significant and the results in this case are $t(88.5)=-2.095, p=0.039$.

The positive value means that the males had a higher average score, that is, males tend to be more materialistic.

\section{Australians and non-Australians}

A $t$-test was undertaken to explore differences between Australian and non-Australian respondents' perceptions towards materialism (Table 1). The results indicate that there is no significant difference between the average materialism score for Australians and non-Australians.

\section{Brand perceptions of high-priced fashion clothing}

\section{Males and females}

A $t$-test was undertaken to examine if any differences between males and females exist in perceptions of the Armani brand (Table 2). There was no statistically significant difference between males and females in their perceptions of Armani fashion clothing.

\section{Australians and non-Australians}

$t$-Tests were undertaken to determine if there is any difference between Australians and non-Australians towards the Armani brand (Table 2).

Non-Australians are defined as respondents who are not citizens/residents of Australia. A statistically significant difference was found for only one item on the Armani scale: 'this brand is purchased primarily for its image'. In this case, the results were $t(96)=-2.57, p=0.011$. The difference is -0.5 ; the negative value indicates that non-Australians had the higher average score, that is, non-Australians consider Armani to be an image brand more than do Australians. This shows that both Australians and non-Australians differ only on the aspect of image but agree on all the other aspects such as high-priced exclusivity and prestige. 


\section{Relationship between consumers' materialism and their perception of brand image and personal satisfaction}

To examine the relationship between materialism and brand perception, a correlation analysis was undertaken. The results indicate that a significant correlation exists between Armani 1 ('owning this brand is a symbol of success in the society') and materialism. The correlation is 0.265 , ie $r$ $(102)=0.27, p<0.05$. As the correlation is positive, respondents who viewed owning Armani as a symbol of success in society possessed a higher degree of materialism. This can also imply that highly materialistic respondents highly rate owning Armani as a symbol of success in society. The correlation between materialism and the other items of brand perception was not significant; therefore, it can be inferred that there is no systematic association between a respondent's materialism and their perception of the brand image, although there is a systematic association with their perception of personal satisfaction.

\section{DISCUSSION}

From the above results, it has been observed that there is a difference in the materialistic tendencies of males and females, whereas there is no difference between Australians and non-Australians. It is interesting to note that there is no difference in the brand perceptions of high-priced fashion clothing between males and females; however, non-Australians differed significantly in their perception of high-priced fashion clothing compared with Australians. Most importantly, it has been found that materialism affects perception of high-priced fashion clothing in terms of personal satisfaction but not in terms of the brand image.

The findings of this study can help in investigating the relationship between material values and marketing stimuli such as advertising, store displays and product characteristics. If the study is taken a step further and done in a comprehensive cross-cultural mode, then it will help in changing the product positioning across countries. Although the global boundaries are disappearing to some extent, a new form of disintegration is being observed in the modern world. Whether viewed as good or bad, this is a trait which will stay on for quite some time into the future. Once the linkage between brand image and materialistic perception is obtained, then the brand image can be changed or re-positioned based on these perceptions.

It would have been interesting to analyse the consumer perception of credit cards in this study. A category on credit cards was not added into the study, however, because in countries like India and Malaysia, credit card usage is very low and among undergraduate students especially it is almost insignificant. Any responses from such a category would have been unrepresentative, so it was excluded.

Although all the research questions were answered in an effective manner, the small size of the sample presents a high risk for external validity. There seem to be differences but, given the number of interactions that could potentially have been significant, the number of differences found is rather low. The non-Australian sample of 70 was made up of Malaysian, Indian, Indonesian, Thai, US, Swedish and Norwegian respondents. Due to the diverse nature of the countries represented, it was not possible to analyse the inter-country differences between the respondents of these countries. The sample size of the respondents from the above-mentioned countries was rather small and this is a limitation that can be 
overcome in future research. It will be interesting to analyse the differences between the Western sample (including the USA, Sweden, Norway and Australia) and the non-Western sample (including Malaysia, India, Indonesia and Thailand). As mentioned in the introduction, the USA is viewed as a country that breeds and encourages the 'evil phenomenon' known as materialism; therefore, for future research it will be worthwhile to do a comparative study between US and non-US respondents to gauge the impact of materialism.

The scale employed in the study and the way it is measured needs refinement. For example, measures that will assess the extent to which individuals use material possessions or goods to define themselves or their group behaviour will aid researchers in examining and analysing in a broader sense the relationships of consumers with material objects or certain brands. In conclusion, consumer perceptions are affected by materialism, gender and nationality.

\section{CONCLUSION}

By continuing to explore issues related to possessions and their position in consumers' lives, we can better understand the effective utilisation of consumer attachment to possessions at both a theoretical and practical level in understanding consumer behaviour related to fashion. This is important because fashion clothing has both important economic and social significance in many societies, particularly Western. Some would argue, however, that a fundamental paradox of fashion and consumers' strong attachment to it exists in the context of personal identity, with its unique and autonomous nature. Dittmar $^{49}$ commented that personal identity should perhaps be independent of material context, and in reality, we are who we are, no matter what our possessions may be. Although branding plays a major role in the fashion (apparel) industry, consumers tend to view brand names from different perspectives such as materialism, gender and nationality. What appears to be the case, however, as partially reflected in this study, in the context of fashion clothing, is that we are what we wear. In reality, we are who our clothes allow us to be.

\section{References}

1 'The Oxford English Reference Dictionary' (1995) Oxford University Press, Oxford; p. 891.

2 Richins, M. L. (1987) 'Media, materialism and human happiness', in Wallendorf, M. and Anderson, P. (eds) Advances in Consumer Research, Vol. 14. Association for Consumer Research, Provo, UT, pp. 352-356.

3 Richins, M. L. and Dawson, S. (1992) 'A consumer values orientation for materialism and its measurement, scale development and validation', Journal of Consumer Research, Vol. 19, No. 3, pp. 303-316.

4 Campbell, C. (1987) 'The romantic ethic and the spirit of modern consumerism', Basil Blackwell, New York, NY.

5 Inglehart, R. (1981) 'Post-materialism in an environment of insecurity', American Political Science Review, Vol. 75, pp. 880-900, No. 4

6 Belk, R. W. (1987) 'Material values in the comics: A content analysis of comic books featuring themes of wealth', Journal of Consumer Research, Vol. 14, No. 1, pp. 26-42.

7 Belk, R. W. (1983) 'Worldly possessions: Issues and criticisms', Advances in Consumer Research, Vol. 10, pp. 514-519.

8 Belk, R. W. (1985) 'Materialism: Trait aspects of living in the material world', Journal of Consumer Research, Vol. 12, No. 3, pp. 265-280.

9 Wachtel, P. L. (1983) 'The poverty of affluence: A psychological portrait of the American way of life', Free Press, New York, NY.

10 Coleman, J. W. (1992) 'Crime and money', American Behavioural Scientist, Vol. 35, No. 6, pp. 827-836.

11 Seabrook, J. (1978) 'What's gone wrong? Why hasn't having more made people happier?', Pantheon, New York, NY.

12 Belk, R. W. (1988) 'Third world consumer culture', Research in Marketing, Suppl. 1.4, pp. 113-127.

13 Friedman, J. E. (1994) 'Consumption and identity', Harwood Academic Publishers, Chur, Switzerland.

14 Ger, G. (1997) 'Human development and humane consumption: Well-being beyond the good life', Journal of Public Policy and Marketing, Vol. 16, No. 1, pp. 110-125.

15 Ger, G. and Belk, R. W. (1996) 'Cross-cultural 
differences in materialism', Journal of Economic Psychology, Vol. 17, No. 1, pp. 55-77.

16 Annamma, J. and Wallendorf, M. (1996)

'Development of consumer culture in the third world: theories of globalism and localism', in Belk, R. W., Dholakia, N. and Venkatesh, A. (eds) 'Consumption and marketing: Macro dimensions', South Western, Cincinnati, OH, pp. 104-142.

17 Kemper, S. (1993) 'The nation consumed: Buying and believing in Sri Lanka', Public Culture, Vol. 5, pp. 377-393.

18 Schultz, C. II, Belk, R. and Guliz G. (eds) (1994) 'Consumption in marketizing economies', JAI Press, Greenwich, CT.

19 Daun, A. (1983) 'The materialistic life-style: Some socio-psychological aspects', in Uusitalo, L. (ed) 'Consumer behaviour and environmental quality', St Martins, New York, NY, pp. 6-16.

20 Bredemeier, H. C. and Campbell, D. T. (1960) 'Social problems in America: Costs and casualties in an acquisitive society,' Wiley, New York, NY.

21 Wackman, D. B., Reale, G. and Ward, S. (1972) 'Racial differences in responses to advertising among adolescents', in 'Television in day to day life', US Department of Health, Education and Welfare, Rockville, MD, pp. 543-551.

33 Heilbroner, R. L. (1956) 'The quest for wealth: A study of acquisitive man', Simon and Schuster, New York, NY.

23 Rassuli, K. M. and Hollander, S. C. (1986) 'Desire Induced, innate, insatiable?' Journal of Macro Marketing, Vol. 6, No. 2, pp. 4-24.

24 Du Bois, C. (1955) 'The dominant value profile of American culture', American Anthropologist, Vol. 57, No. 6, pp. 1232-1239.

25 Csikszentmihalyi, M. and Rochberg-Halton, E. (1978) 'Reflections on materialism', University of Chicago Magazine, Vol. 70, No. 3, pp. 6-15.

26 Csikszentmihalyi, M. and Rochberg-Halton, E. (1981) 'The meaning of things: Domestic symbols and the self', Cambridge University Press, Cambridge, UK.

27 Dickins, D. and Ferguson, V. (1957) 'Practices and attitudes of rural white children and parents concerning money', Mississippi Agricultural Experiment Station Technical Bulletin, Vol. 43.

28 Burdsal, C. Jr (1975) 'An examination of second order motivational factors as found in adults', Journal of Genetic Psychology, Vol. 127 (September), pp. 83-89.

29 Justice, B. and Birkman, R. (1972) An effort to distinguish the violent from the non violent. Southern Medical Journal, Vol. 65, No. 6, pp. 703-706.

30 Heslin, R., Johnson, B. T. and Blake, B. F. (1989) 'Saver-spender scales', Proceedings of the Society for Consumer Psychology, Annual Convention 1988, Society for Consumer Psychology, Washington, DC, pp. 179-185.

31 Dubois, B and Duquesne, P. (1993) 'The market of luxury goods: Income versus culture', European Journal of Marketing, Vol. 27, No. 1, pp. 35-45.

32 Mason, R. M. (1981) 'Conspicuous consumption: A study of exceptional consumer behaviour', Gower
Publishing Company, Farnborough, UK.

33 Holman, R. H. (1981). 'Product as communication: A fresh appraisal of a venerable topic', in Eris, B. M. and Boering, K. J. (eds) 'Review of marketing', American Marketing Association, Chicago IL, pp. 106-119.

34 Solomon, M. R. (1983) 'The role of products as social stimuli: A symbolic interactionism perspective', Journal of Consumer Research, Vol. 10, No. 3, pp. 319-329.

35 Campbell, D. T. (1969) 'Various social attitude scales in measures of political attitudes', in Robinson, J. P. and Shaver, P. R. (eds) 'Measures of political attitudes', University of Michigan, Ann Arbor, MI, pp. 648-653.

36 Mowen, J. C. (1995) 'Consumer behaviour', 4th edn, Prentice Hall, Englewood Cliffs, NJ.

37 Solomon, M. R. (1999) 'Consumer behaviour', 4th edn, Prentice Hall, Upper Saddle River, NJ.

38 Belk, R. W. (1984) 'Three scales to measure constructs related to materialism: Reliability, validity and relationships to measures of happiness', Advances in Consumer Research, Vol. 11, pp. 291-297.

39 Fournier, S. and Richins, M. L. (1991) 'Some theoretical and popular notions concerning materialism', Journal of Social Behaviour and Personality, Vol. 6, pp. 403-414.

40 O'Cass, A. and Thomas Muller, T. (1999) 'A study of Australian materialistic values, product involvement and self-image/product-image congruency relationships for fashion clothing', Proceedings of The Ninth Biennial World Marketing Congress, Academy of Marketing Science.

41 O'Cass, A. (2001) 'Consumer self-monitoring, materialism and involvement in fashion clothing', Australasian Marketing Journal, Vol. 9, No. 1, pp. 46-60.

42 Kaiser, S. B. (1990) 'The social psychology of apparel', 2nd edn, Macmillan, New York, NY.

43 O’Shaugnessey, J. (1987) 'Why people buy', Oxford University Press, New York, NY.

44 Morganosky, M. A. and Vreeman, A. L. (1986) 'The involvement concept: Relationships to the apparel consumer', unpublished manuscript - Source: Journal of Product and Brand Management, Vol. 7, No. 3, 1998, p. 205.

45 Douglas, M, and Isherwood B. (1979) 'The world of goods', Allen Lane, London.

46 Beaudoin, P., Moore, M. A. and Goldsmith, R. E. (1998) 'Young fashion leaders' and followers' attitudes toward American and imported apparel', Journal of Product and Brand Management, Vol. 7, No. 3, pp. 193-207.

47 Grimm, L. G. and Yarnold, P. R. (1998) 'Reading and understanding multivariate statistics', APA, Washington, DC.

48 Hair, J. F. Jr, Anderson, R. E., Tatham, R. L. and Black, W. C. (1998) 'Multivariate data analysis', 5th edn, Prentice-Hall, Englewood Cliffs, NJ.

49 Dittmar, H. (1992) 'The social psychology of material possessions', Harvester Wheatsheaf, Hemel Hempstead, UK. 